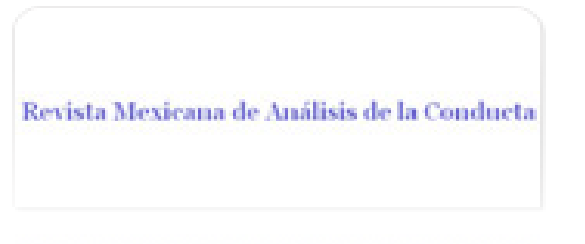

Revista Mexicana de Análisis de la Conducta ISSN: 0185-4534

editora@rmac-mx.org

Sociedad Mexicana de Análisis de la Conducta México

Bazán-Ramírez, Aldo; Urbina-Pérez, Diana; Domínguez-Márquez, Lorena; Mansillas-Cervantes, María

I.; Gómez-Manjarrez, Itzel

DESARROLLO FUNCIONAL DE COMPETENCIAS DE PRODUCCIÓN DE TEXTOS EN ALUMNOS

CON BAJO DESEMPEÑO EN EL ÚLTIMO AÑO DE PRIMARIA

Revista Mexicana de Análisis de la Conducta, vol. 37, núm. 1, abril-julio, 2011, pp. 89-107

Sociedad Mexicana de Análisis de la Conducta

Guadalajara, México

Disponible en: http://www.redalyc.org/articulo.oa?id=59319102007

Cómo citar el artículo

- Número completo

- Más información del artículo

Página de la revista en redalyc.org

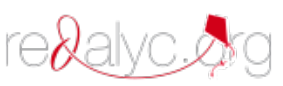

Sistema de Información Científica

Red de Revistas Científicas de América Latina, el Caribe, España y Portugal Proyecto académico sin fines de lucro, desarrollado bajo la iniciativa de acceso abierto 
REVISTA MEXICANA DE ANÁLISIS DE LA CONDUCTA MEXICAN JOURNAL OF BEHAVIOR ANALYSIS

DOI:10.5514/rmac.v37.i1.24741
NUM $1(4-11 / 7-11)$

\title{
DESARROLLO FUNCIONAL DE COMPETENCIAS DE PRODUCCIÓN DE TEXTOS EN ALUMNOS CON BAJO DESEMPEÑO EN EL ÚLTIMO AÑO DE PRIMARIA
}

\author{
FUNCTIONAL DEVELOPMENT OF COMPETENCES IN TEXT \\ PRODUCTION IN OF STUDENTS WITH LOW PERFORMANCE IN \\ THEIR LAST GRADE OF ELEMENTARY SCHOOL \\ ALDO BAZÁN-RAMÍREZ (1), DIANA URBINA-PÉREZ (2), \\ LORENA DOMÍNGUEZ-MÁRQUEZ (1), MARÍA I. MANSILLAS-CERVANTES (3) \\ E ITZEL GÓMEZ-MANJARREZ (1)
}

(1) Universidad Autónoma del Estado de Morelos, Facultad de Psicología

Cuernavaca, Estado de Morelos

(2) Universidad Michoacana de San Nicolás de Hidalgo, Escuela de Psicología

Morelia, Estado de Michoacán

(3) Universidad de Occidente Campus Guasave, Carrera de Psicologia

Guasave, Estado de Sinaloa

Resumen

Se presentan resultados de un estudio con evaluación pre y pos con tres grupos de comparación, realizado con el fin de probar tres tipos de estrategias de entrenamiento en producción de textos, las cuales son morfológica, jerárquica y funcionalmente distintas. Esto con la intención de promover tres diferentes tipos de desligamiento funcional: intrasituacional, extrasituacional y transituacional. El programa de intervención fue implementado como taller de verano dirigido a 14 niños de sexto grado de una escuela primaria pública semi urbana, en el Estado de Morelos, México, con bajos niveles de desempeño en actividades de producción de textos.

Las competencias de producción de textos fueron evaluadas con cuatro series de dos actividades: redactar reglamentos, redactar cuentos, elaborar párrafos descriptivos y escribir mensajes utilizando sinónimos. Para comparar los desempeños

Esta investigación se realizó con apoyo de PROMEP para proyectos de generación y aplicación de conocimientos a nuevos profesores de tiempo completo, 2006-2010. Los coautores contribuyeron igualmente al escrito, bajo la coordinación de Aldo Bazán, que es profesor-investigador en la UAEM; Lorena Domínguez e Itzel Gómez son estudiantes de la Maestría en Psicología de la UAEM. Dirigir la correspondencia al primer autor, Calle Flor de Noche Buena N. 62, Fraccionamiento Jardines de Ahuatlán, Cuernavaca, Morelos, México. C.P. 62130,correo: aldo78b@yahoo.com.mx 
en evaluaciones antes y después, y entre grupos, fueron realizados análisis descriptivos de los promedios por grupo, utilizando un rango de valoración entre 0 y 4 por cada actividad. Asimismo fue probado un modelo de regresión estructural incluyendo como variable predictor a la situación experimental (grupo) y como variables a predecir, as cuatro competencias evaluadas.

Los resultados mostraron que los niños del grupo transituacional mejoraron notablemente sus competencias de producción de textos en comparaciones pre y pos evaluación, asimismo, el modelo de regresión estructural mostró que en el post test la condición experimental tu un efecto significativo en los desempeños diferenciales, en tres de las cuatro competencias evaluadas.

Palabras clave: Interacción, alumnos de educación básica, lectura, escritura, producción de textos.

Abstract

Preliminary results of a study with pre - post evaluation with three comparison groups are shown. This study has the purpose of testing three types of strategies for training in text production, which are morphologically, hierarchically and functionally different. This in order to promote three different types of functional relations: intrasituational, extrasituational and transituational. The intervention program was implemented as a summer workshop directed to 14 children of sixth grade in a semi urban area in the State of Morelos, Mexico, having low levels of performance in text production activities. The text production skills were assessed with four sets of two activities each one: writing regulations, writing stories, develop descriptive paragraphs and writing messages with use of synonymous. To compare the performance assessments before and after, and between groups, were descriptive analysis of group averages, using a valuation range between 0 and 4 for each activity. Also tested a structural regression model including as predictor variable to the experimental situation (group) and as variables to predict, the four skills evaluated.

The results showed that the children of the transituacional group remarkably improved their competitions in text production from pre and post evaluations, furthermore, the structural regression model showed that in the post test, the experimental condition had a significant effect on the differential performance in three of the four skills assessed.

Keywords: Interaction, basic schools' students, reading, lecture, text production.

\section{Introducción}

A través de la escritura los individuos establecen contactos directos e indirectos con eventos, objetos o personas con las que entran en relación funcional. Esa interacción es eminentemente lingüística y se configura como proceso histórico 
de diversas formas de adaptaciones con respecto a los eventos referentes (Austin, 1962; Cassany, 1999; Van Dijk, 2000; Wittgenstein, 1953). Cuando alguien escribe algo para sí mismo o para otra persona, entra en contacto con un evento o un objeto directa o indirectamente para poner en contacto a su lector con un evento de referencia.

Esta actividad lingüística (escribir un texto sobre algo para que alguien lo lea, o leer un texto que alguien ha escrito sobre un tema) implica una relación de tres elementos que configuran un evento lingüístico: un referidor (escritor), un referido (lector) y un referente o evento sobre el cual se comunica algo a alguien (Kantor, 1971). Así, el texto pone en contacto al lector con un evento de referencia al igual que el habla pone en contacto al referidor con un evento de referencia que es presentado en forma oral (Kantor, 1924; 1936;1977).

Esta visión naturalista de Kantor fue ampliada por Ribes y López (1985) con una taxonomía funcional que permite ubicar cinco distintos niveles jerárquicos de organización de las interacciones psicológicas, tomando como criterio el concepto de desligamiento funcional, lo cual plantea que el comportamiento de los individuos puede mostrar distintos niveles de autonomía o independencia con respecto a las condiciones espacio temporales de la situación particular, así como de las propiedades físico químicas de los estímulos específicos con los que interactúa un individuo.

Trigo, Martínez y Moreno (1988) han planteado que estos cinco niveles de interacción se estructuran en tres niveles generales de desligamiento funcional:

1. Desligamiento intrasituacional: En este nivel el individuo interactúa con eventos, personas u objetos que se encuentran dentro de la situación o episodio interactivo, sin desligarse de las relaciones concretas situacionales en las que se presentan, ni del contexto en el que interactúan. Por ejemplo, el niño trata con los objetos con base en sus propiedades físicas, responde a preguntas literales, o lee un texto y responde preguntas seleccionando una respuesta a partir de varias respuestas implicadas en el texto. En este nivel se dan tres tipos de interacción: Contextual, la conducta del individuo es reactiva a relaciones de condicionalidad y a propiedades concretas de los eventos de estímulo con los que interactúa; Suplementaria, la conducta del individuo modifica la relación entre los eventos del ambiente, así, el individuo genera cambios en su relación con el referente modulando su comportamiento a la variabilidad producida en tiempo y espacio; Selectora, la conducta del individuo está en relación con la correspondencia que guarda un segundo evento con el evento ante cuyas características fisicoquímicas responde.

2. Desligamiento extrasituacional: La conducta del individuo es independiente (desligada) con respecto a las propiedades situacionales aparentes del aquí y ahora de los objetos y eventos relacionados. La correspondencia entre la conducta del individuo con los objetos, eventos y relaciones, no está restringida a la situacionalidad momentánea y rígida del contexto de interacción, puesto que el 
individuo sustituye una situación o le atribuye funciones no aparentes a objetos, eventos o personas.

En este nivel se da la interacción sustitutiva referencial, que consiste en la transformación de relaciones que dependen de las propiedades situacionales de los eventos, en relaciones que dependen de las propiedades convencionales.

3. Desligamiento transituacional: La conducta del individuo se desliga casi absolutamente respecto de las relaciones situacionales inmediatas y mediatas que inciden sobre el individuo como eventos fisicoquímicos y biológicos. El individuo interactúa con situaciones sustituidas o representadas que dependen de su propia conducta no situacional y propiamente lingüística. Por ejemplo, cuando se le pide a un niño que emita su opinión acerca de lo que significa un refrán, el niño interactúa con un evento lingüístico producto de la convención y no con un referente concreto. La opinión sobre el significado de un refrán implica una interacción en un plano lingüístico y convencional, puesto que un refrán es una sentencia de origen popular, en la cual se expresa un pensamiento moral, un consejo o una enseñanza.

En este nivel de desligamiento la interacción sustitutiva no referencial, es un nivel en el donde se ubican las interacciones entre acciones lingüísticas o convencionales. Estas interacciones son simbólicas ya que las propiedades de los referentes son convencionales o culturales y no físicas.

Por otra parte, existe una amplia base de antecedentes empíricos desde la perspectiva interconductual que contribuyen a desarrollar competencias de lectura y de escritura en niveles funcionalmente complejos, y posibilita la generabilidad a situaciones novedosas que demandan también niveles de ejecución complejos (Bazán \& Mares, 2002; Mares, Guevara \& Rueda, 1996; Mares, Rivas \& Bazán, 2001; Mares, Rivas \& Bazán, 2002; Mares, Rueda, Plancarte \& Guevara, 1997). Estos estudios realizados con alumnos de primaria de diferentes estados de la República Mexicana han mostrado que el nivel funcional en el que se adquiere o ejercita una competencia lingüística (hablada o escrita) afecta la probabilidad de que dicha competencia ocurra ante eventos distintos a los del contexto de adquisición, y que se incorpore a nuevos campos sustitutivos.

Sin embargo no se han realizado estudios desde esta perspectiva interconductual, sobre competencias de producción de textos en situaciones de aprendizaje escolar y con contenidos temáticos incluidos en el programa de estudio y en los libros de texto gratuito con los cuales se trabajan en general en el aula, y mucho menos con estudiantes que presentan bajos niveles de desempeño en evaluaciones sistemáticas y con validez de contenido y de constructo.

Probar estrategias de intervención con estudiantes de bajo desempeño en producción de textos de acuerdo con diferentes niveles de desligamiento funcional de interacciones en situaciones de enseñanza-aprendizaje de producción de textos, proporcionaría una base experimental para plantear la utilidad de trabajar competencias de escritura en los tres niveles de desligamiento funcional bajo el 
supuesto de que estos niveles son cualitativamente jerárquicos e inclusivos entre sí, buscando siempre alcanzar en la situación de aprendizaje, interacciones funcionalmente complejos para que los niños desarrollen competencias de producción de textos en niveles también funcionalmente complejos.

El propósito principal del presente trabajo fue probar el efecto diferencial de un programa de intervención con 3 condiciones experimentales (intrasituacional, extrasituacional y transituacional) sobre el desempeño en evaluación de cuatro competencias de producción de textos en estudiantes con bajo nivel de desempeño, de acuerdo con propósitos y contenidos de quinto grado primaria de acuerdo con los programas de estudio y los libros de texto de la SEP vigentes para el ciclo escolar 2006.

\section{Método}

\section{Participantes}

Participaron 14 alumnos que concluyeron el sexto grado de primaria en una escuela de la comunidad Tres Marías en el Estado de Morelos, México, quienes asistieron voluntariamente a partir de la invitación general a 27 niños de sexto grado de primaría quienes habían sido diagnosticados con indicadores de bajo desempeño en producción de textos un mes antes de concluir el ciclo escolar 2006 (Bazán, Rivera, Monrroy \& Rodríguez, 2006). Fueron ocho niñas y seis niños.

Diseño

Se utilizó un diseño cuasi experimental con tres grupos de comparación y con mediciones antes y después.

Con la muestra de 14 niños que asistieron a la primera reunión fueron conformados al azar tres grupos experimentales que fueron asignados también aleatoriamente a cada condición experimental: Intrasituacional (5 alumnos), Extrasituacional (5 alumnos) y Transituacional (4 alumnos). Pese a que fue considerado un grupo control, los niños considerados para este grupo no asistieron al post test, por lo cual en este estudio solamente fueron considerados los tres grupos experimentales.

El programa de intervención sobre producción de textos fue impartido en un total de 16 horas, de manera simultánea en los tres grupos experimentales. Durante la primera semana de agosto de 2006 en cuatro sesiones, cada una con cuatro horas de duración (de 10 a 14 hrs.), incluyendo un receso diario de treinta minutos. Se trabajó en aulas separadas según la condición experimental, utilizando dos aulas de la iglesia local y otra aula del local municipal.

Se desarrolló una sesión de repaso con las actividades desarrolladas en las cuatro sesiones, 48 horas después a la cuarta sesión. Fueron utilizadas las mismas técnicas grupales (dinámicas) en cada grupo experimental, al inicio de las actividades y en los recesos, con la finalidad de generar mayor interés y atención de parte de los niños. 
Materiales e instrumentos

Los materiales de apoyo para trabajar en las situaciones de enseñanza aprendizaje fueron:

a) Sinons (memorama de sinónimos). Es un juego de mesa que consta de de diez pares de tarjetas con palabras y diez pares de tarjetas con sinónimos. Sólo en una de ellas aparece la frase "vuelve a intentar". La finalidad de este juego fue ampliar el vocabulario del niño y ejercitar la redacción y ejecución de discursos.

b) Ortolotería (lotería para mejorar la ortografía). Este juego consta de cinco tarjetas con seis casillas cada una y dieciocho barajas que contienen reglas de ortografía (acentuación, identificación; clasificación). El objetivo de este material es fomentar en el niño las reglas ortográficas a través del juego y mejorar su nivel de ortografía y escritura.

c) Cuento escrito "un bosque encantado". Su finalidad es lograr que los niños redacten un cuento a partir de sus componentes básicos: inicio, desarrollo y final, además de describir el comportamiento y las características físicas de los personajes.

d) Reglamento de tránsito. Esta actividad tiene como meta que los niños desarrollen habilidades en la redacción de reglamentos, a partir de imágenes y símbolos.

e) Adicionalmente se requirió de hojas de papel bond, lápices, gomas, sacapuntas, plumones, cartulinas y hojas de registro previamente elaboradas y cuadernillos con categorías de análisis. También fueron utilizadas tres cámaras de video VHS y cuatro video casetes.

f) Para evaluar la producción de textos fueron utilizadas cuatro series de tareas que corresponden a cuatro competencias: 1. Redacción de reglamentos, 2. Escribir mensajes utilizando sinónimos, 3. Elaborar cuentos a partir de títulos y 4. Elaborar descripciones a partir de personajes de historias cortas. Estas series de tareas fueron derivadas de medidas que cumplen con validez convergente y divergente de constructo (Bazán, Castañeda, Macotela \& López, 2004) y elaborados con base en los programas de estudio de Español de la SEP (2000) y los libros de texto gratuito (SEP, 2002).

Cada una de las cuatro series que evalúa una de las cuatro competencias, incluyó dos tareas o actividades de evaluación (tarea 1) y (tarea 2).

\section{Procedimiento}

Pre evaluación

Se tomaron como datos de preevaluación, el desempeño de cada niño en las cuatro competencias de actividades de producción de textos descritas en la sección anterior, evaluado previamente al término del sexto grado de primaria en junio de 2006. 


\section{Intervención}

En la primera reunió se presentó a los investigadores que desarrollarían la propuesta; se explicó a los niños de qué trataría el taller y los objetivos que se perseguían, así como la forma en que se desarrollaría el trabajo durante los cuatro días. Posteriormente, se hicieron los equipos de trabajo y fueron asignados dos investigadores a situación experimental.

A continuación son descritas las actividades desarrolladas en cada una de las cuatro sesiones de intervención:

Sesión 1: Ortografía.

El objetivo de esta actividad fue desarrollar la habilidad de escribir respetando reglas ortográficas y fue aplicada de la misma manera en los tres grupos experimentales.

En cada grupo experimental se explicó a los niños qué son las reglas ortográficas y cuál es su utilidad, se dieron ejemplos de cada tipo de palabras (agudas, graves, esdrújulas y sobresdrújulas). Luego de realizar un juego, cada niño debió resolver acertadamente un grupo de tareas de reconocimiento de palabras y colocar el acento o tilde donde correspondiera.

Posteriormente se desarrolló por grupos el juego de lotería. Se asignó a cada niño una tarjeta de Ortolotería que contenía las reglas de ortografía, el nombre de las palabras y sus definiciones; también se les dieron sus fichas correspondientes; se explicaron las instrucciones del juego y se inició cuando el instructor nombró la primera carta y entonces los jugadores tenían que identificarla en su tarjeta, se concluyó cuando el instructor terminó de leer todas las cartas.

Una vez que los niños jugaron cuatro veces intercambiando tarjetas, de manera individual pero en sesión grupal, se les preguntó el nombre de las palabras en sus tarjetas, se les pidió que den definiciones y digan el uso de reglas de ortografía para las palabras de sus tarjetas.

Sesión 2: Sinónimos.

De manera simultánea en los tres grupos, se tuvo una sesión de repaso para reforzar el uso de las palabras trabajadas el día anterior. En esta segunda sesión se trabajó con la elaboración de mensajes con sinónimos, para lo cual se les explicó a los niños sobre qué son los sinónimos y cuál es su utilidad, asimismo se realizó un ensayo con diez palabras para las cuales debían dar dos sinónimos diferentes.

Luego se trabajó en grupos el juego Memorama. Se les presentaron diez pares de tarjetas y una más con la frase "vuelve a intentar" y se les explicaron las reglas del juego y se inició volteando un par de cartas. En este juego los niños identificaron el sinónimo correspondiente a la palabra indicada en la primer tarjeta volteada (este juego duró aproximadamente entre 45 y 50 minutos).

Con el fin de comprobar la efectividad del juego se les aplicaron tres activi- 
dades. La primera consistió en unir con una línea dos columnas (una de palabras y otra de sinónimos). En la siguiente actividad los instructores les dictaron a los niños once palabras y ellos debían escribir su sinónimo. En la última actividad, los niños tenían que elaborar tres oraciones utilizando sinónimos de tres palabras proporcionadas.

El ejercicio más sobresaliente fue que para cada nueva palabra, el niño debía pensar en dos sinónimos de ésta, y con ellas escribir un mensaje incluyendo las tres palabras en un mismo párrafo.

Posteriormente, se revisó la tarea de cada uno de los niños y se resolvieron las dudas. Con la finalidad de que los niños reafirmaran este aprendizaje, se les pidió que resolvieran un ejercicio de relación de palabras con sus respectivos sinónimos. Se realizaron cuatro ensayos por cada par de palabras.

Sesión 3: Producción de cuento y descripción de personajes.

$\mathrm{Al}$ inicio de la sesión se realimentó el trabajo de los primeros dos días mediante preguntas y ejercicios similares a los anteriores. El objetivo principal de la sesión 3 fue desarrollar la habilidad de redacción de un cuento que tuviese un inicio, un desarrollo y un final, así como la elaboración de descripciones a partir de los personajes. El entrenamiento se llevó a cabo tomando en cuenta los niveles de desligamiento funcional, donde cada grupo trabajó la misma actividad pero con procedimientos diferentes, un ejemplo de estas actividades es mostrado en la Tabla 1.

Sesión 4: Producción de reglamentos.

$\mathrm{Al}$ igual que en las anteriores sesiones, se inició con un repaso de lo enseñado en la sesión anterior. La última actividad del programa fue la elaboración de reglamentos utilizando un ejercicio denominado "previniendo accidentes de tránsito". Se desarrollaron actividades diferentes por niveles de desligamiento funcional, como se describe en la Tabla 2. El objetivo de esta actividad fue desarrollar la habilidad en la redacción de reglamentos.

Pos evaluación

Los niños de los tres grupos experimentales fueron evaluados en la segunda semana de agosto de 2006, y un día después de la sesión de repaso, con las mismas actividades consideradas en la pre evaluación (redactar reglamentos, elaborar mensajes por escrito utilizando sinónimos, redactar cuentos a partir de títulos y elaborar por escrito descripciones a partir de personajes de historias cortas).

Registro de los desempeños.

Posterior al post test se registraron y analizaron las respuestas de los niños durante las fases de pre y pos test. Previamente, todos los registradores recibieron un entrenamiento para usar las categorías y criterios especificados utilizando una hoja 
Desarrollo funcional

Tabla 1.

Actividades de producción de cuento y descripción de personajes, según el nivel de desligamiento funcional

\begin{tabular}{|c|c|c|}
\hline $\begin{array}{c}\text { GRUPO } \\
\text { INTRASITUACIONAL }\end{array}$ & $\begin{array}{c}\text { GRUPO } \\
\text { EXTRASITUACIONAL }\end{array}$ & $\begin{array}{c}\text { GRUPO } \\
\text { TRANSITUACIONAL }\end{array}$ \\
\hline $\begin{array}{l}\text { 1. Se explicó a los niños } \\
\text { qué es un cuento, sus } \\
\text { partes (inicio, desarrollo y } \\
\text { final), sus características, } \\
\text { así como la descripción de } \\
\text { personajes. } \\
\text { 2. Lectura grupal del } \\
\text { cuento } \\
\text { 3. A cada niño se le dio } \\
\text { una hoja en blanco y otra } \\
\text { con el texto del cuento } \\
\text { con imágenes para que lo } \\
\text { transcriba. } \\
\text { 4. Los niños identificaron } \\
\text { las partes del cuento que } \\
\text { transcribió, ordenando las } \\
\text { imágenes de acuerdo con } \\
\text { la secuencia del mismo. } \\
\text { 5. Cada niño debió } \\
\text { identificar en su cuento } \\
\text { (transcrito) las partes que lo } \\
\text { componen } \\
\text { 6. Los niños debieron } \\
\text { Ilenar por escrito una lista } \\
\text { de personajes principales y } \\
\text { secundarios, consultando } \\
\text { su cuento } \\
7 \text {. Al finalizar los investi- } \\
\text { gadores hicieron un repaso } \\
\text { con ayuda de los niños, de } \\
\text { lo qué es un cuento, sus } \\
\text { partes y características, así } \\
\text { como la descripción de } \\
\text { personajes. }\end{array}$ & $\begin{array}{l}\text { 1. Se explicó a los niños } \\
\text { qué es el cuento, sus partes } \\
\text { (inicio, desarrollo y final), } \\
\text { sus características, así } \\
\text { como la descripción de } \\
\text { personajes. } \\
\text { 2. Lectura grupal del } \\
\text { cuento } \\
\text { 3. Se repartió a cada } \\
\text { niño una hoja con las imá- } \\
\text { genes correspondientes al } \\
\text { cuento, y una hoja blanca. } \\
\text { 4. Los niños ordenaron } \\
\text { secuencialmente las imá- } \\
\text { genes de acuerdo con la } \\
\text { lectura previa. } \\
\text { 5. Cada niño redactó un } \\
\text { cuento de acuerdo a las } \\
\text { imágenes que ellos orde- } \\
\text { naron previamente. } \\
\text { 6. Cada niño debió } \\
\text { identificar en su cuento } \\
\text { redactado, las partes que } \\
\text { lo componen. }\end{array}$ & $\begin{array}{l}\text { 1. Se explicó a los niños } \\
\text { qué es el cuento, sus } \\
\text { partes (inicio, desarrollo y } \\
\text { final), sus características, } \\
\text { así como la descripción de } \\
\text { personajes. } \\
\text { 2. Lectura grupal del } \\
\text { cuento } \\
\text { 3. Se repartió a cada } \\
\text { niño una hoja con cin- } \\
\text { co preguntas de opinión } \\
\text { referentes a la historia que } \\
\text { narra el cuento. } \\
\text { 4. Los niños redactaron } \\
\text { un cuento, de acuerdo a lo } \\
\text { que él opinó previamente. } \\
\text { 5. Cada niño tomó la } \\
\text { función de referido, leyó } \\
\text { el cuento de otro niño } \\
\text { emitiendo por escrito una } \\
\text { crítica o comentario sobre } \\
\text { el escrito de ese niño, con- } \\
\text { siderando las partes que } \\
\text { conforman un cuento. } \\
\text { 6. Los niños escribieron } \\
\text { un párrafo emitiendo su } \\
\text { opinión sobre la forma de } \\
\text { proceder de los personajes } \\
\text { principales del cuento } \\
\text { 7. Al finalizar los investi- } \\
\text { gadores hicieron un repaso } \\
\text { con ayuda de los niños, de } \\
\text { lo qué es un cuento, sus } \\
\text { partes y características, así } \\
\text { como la descripción de } \\
\text { personajes. }\end{array}$ \\
\hline
\end{tabular}


Tabla 2.

Actividades de elaboración de reglamentos según el nivel de desligamiento funcional

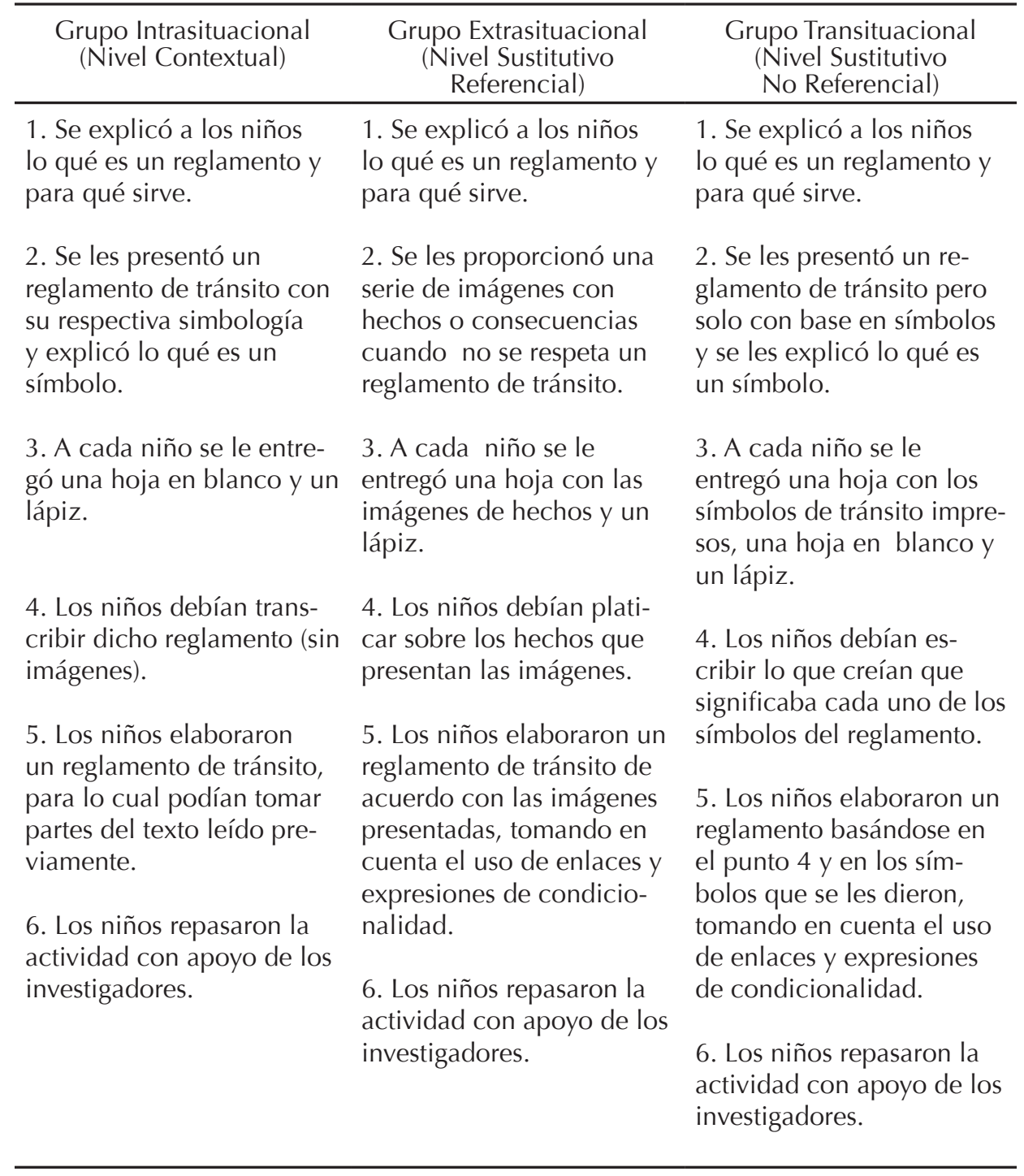


de registro, hasta obtener un índice aceptable de confiabilidad entre observadores (0.90). Para dicho entrenamiento se emplearon las evaluaciones de los mismos ejercicios de estudiantes de otra escuela. Los registros se realizaron en parejas de manera independiente, dos personas registraron un mismo instrumento por separado, y posteriormente el equipo de investigación resolvió por modalidad de panel de expertos, los casos de discrepancia entre registradores.

\section{Resultados}

En primera instancia fueron obtenidos los índices de consistencia interna de la evaluación de las cuatro competencias antes y después de la intervención.

En un análisis comparativo antes y después se encontró que los niños de los tres grupos que recibieron el programa de intervención de tres formas funcionalmente distintas, incrementaron sus promedios de nivel de desempeño también de manera diferencial en las cuatro competencias de producción de textos, en pre y post evaluación.

Tabla 3.

Descripción comparativa de desempeños en las cuatro competencias evaluadas (promedios) por cada grupo en pre y pos evaluación.

\begin{tabular}{llccc}
\hline Grupo & $\begin{array}{l}\text { Actividad } \\
\text { (competencia) }\end{array}$ & Media & & $\begin{array}{c}\text { Diferencia pre y } \\
\text { pos evaluación }\end{array}$ \\
\hline & Reglamentos & $\begin{array}{c}\text { pre } \\
\text { evaluación }\end{array}$ & $\begin{array}{c}\text { pos } \\
\text { evaluación }\end{array}$ & \\
\hline \multirow{5}{*}{ Intrasituacional } & Cuentos & 2.50 & 1.50 & 0 \\
& Descripciones & 1.75 & 2.87 & 0 \\
& Sinónimos & .62 & 2.12 & 0.37 \\
\hline \multirow{5}{*}{ Extrasituacional } & Reglamentos & 1.20 & 1.60 & 0.40 \\
& Cuentos & 2.40 & 2.90 & 0.50 \\
& Descripciones & 1.90 & 2.20 & 0.30 \\
& Sinónimos & .20 & 2.00 & 1.80 \\
\hline & Reglamentos & 1.37 & 2.62 & 1.25 \\
& Cuentos & 2.60 & 3.00 & 0.40 \\
& Descripciones & .57 & 2.62 & 2.05 \\
& Sinónimos & 1.25 & 2.25 & 1.00 \\
\hline
\end{tabular}


Figure X: EQS 6 acta 08 pre Chi Sq. $=16.72 \mathrm{P}=0.01 \mathrm{CFI}=0.00$ RMSEA $=0.39$

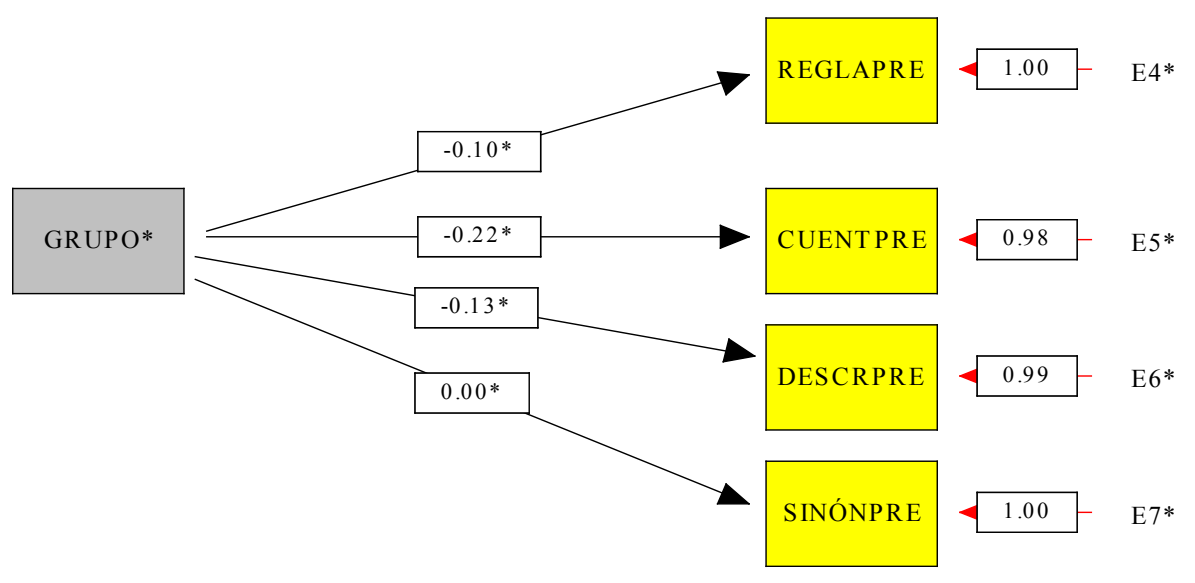

Figura 1. Modelo de regresión estructural entre la condición experimental y las cuatro competencias de producción de textos, en la pre evaluación.

En la Tabla 3 se presenta una descripción comparativa de los desempeños de los niños de cada grupo en la pre y en la post evaluación. Para este análisis, en cada competencia se obtuvo un único indicador que resultó de promediar los valores directos obtenidos por cada niño en las dos tareas que conformaban cada competencia ( o series de actividades).

Asimismo fue incluido un indicador de diferencia pre y post evaluación, que consistió en restar el promedio obtenido en el pre test, del promedio obtenido en el post test.

Grupo Intrasituacional (Nivel Contextual)

El desempeño de los niños incrementó considerablemente en escribir mensajes utilizando sinónimos, así como en la elaboración escrita de descripciones. Sin embargo, en dos actividades no se dieron incrementos: elaboración de reglamentos y elaboración de cuentos.

Grupo Extrasituacional (Nivel Sustitutivo Referencial)

A diferencia del nivel anterior, en el grupo Extrasituacional hubo un aumento en el desempeño de los niños en las cuatro actividades; sobre todo se nota que es drástico el cambio en la actividad de escribir sinónimos, ya que pasó de un promedio de 0.20 a un promedio de 2 (Tabla 3 ). 


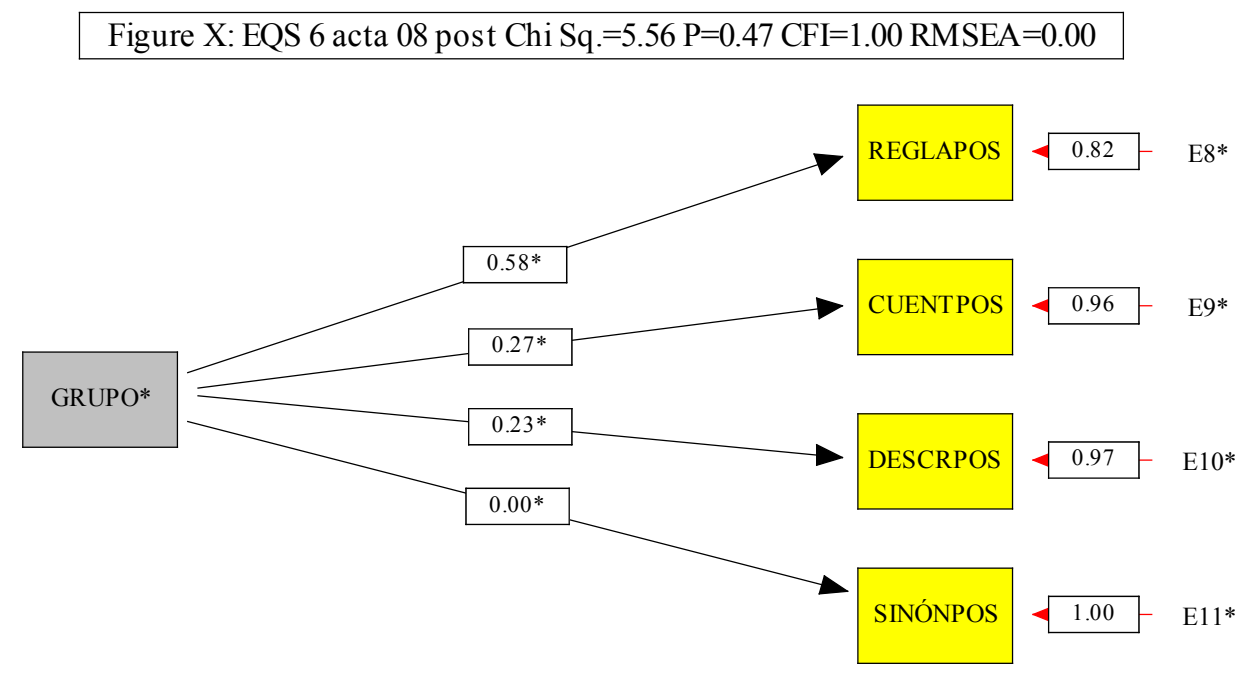

Figura 2. Modelo de regresión estructural entre la condición experimental y las cuatro competencias de producción de textos, en la pos evaluación.

Grupo Transituacional (Nivel Sustitutivo No Referencial)

En la tabla 3 se observa que los niños de este grupo incrementaron su nivel de desempeño en las cuatro actividades, siendo los cambios más notorios en los ejercicios de elaboración de descripciones y elaboración de reglamentos.

Como complemente, fueron incluidos y probados a través del programa EQS 6.1 de ecuaciones estructurales, dos modelos de regresión estructural bajo la hipótesis de que la situación experimental de entrenamiento tiene efecto diferencial en el nivel de desempeño de los 14 estudiantes en la post evaluación.

El primer modelo correspondió a la pre evaluación y el segundo a la post evaluación. Cada modelo de regresión estructural incluyó al grupo o condición experimental como la variable independiente o variable predictora y a las cuatro competencias evaluadas como las variables dependientes o variables a ser predichas.

En la Figura 1 puede ser observada que en la preevaluación la variable grupo no tuvo efecto sobre las competencias evaluadas, además de que el modelo no obtuvo bondad de ajuste aceptable $(\mathrm{P}<0.05$ y el índice práctico de bondad de ajuste CFI fue inferior a 0.97).

Por el contrario, la Figura 2 muestra que en la pos evaluación fue encontrado un modelo satisfactorio, en el cual la variable grupo tuvo un impacto positivo y significativo especialmente en la competencia "redacción de reglamentos". Este 
modelo obtenido es similar al modelo hipotético, por lo que se acepta el modelo resultantes tiene buena bondad de ajuste (El indicador práctico de bondad de ajuste fue superior a $0.97(\mathrm{CFI}=1.00)$.

\section{Discusión}

Pese a la corta duración del programa de intervención, en general, los estudiantes que concluyeron la primaria con bajos niveles de desempeño en cuatro tipos de actividades de producción de textos, incrementaron sus promedios de nivel de desempeño en comparación pre y pos evaluación. Sin embargo, estos cambios fueron diferentes según el nivel de desligamiento que los investigadores promovieron en la fase de intervención a pesar que en los tres grupos fueron trabajados los mismos contenidos temáticos. Por ejemplo, de acuerdo con los datos obtenidos, el nivel de desligamiento intrasituacional solo permitió incrementos en dos de las cuatro competencias evaluadas (elaboración por escrito de párrafos descriptivos y elaboración de mensajes con sinónimos), mientras que en los grupos en que se promovieron niveles de desligamiento funcional de tipo extra y transituacional, los niños incrementaron sus desempeños en las cuatro competencias de producción de textos (elaboración de párrafos descriptivos, elaboración de mensajes usando sinónimos, elaboración de reglamentos y elaboración de cuentos).

En los párrafos siguientes son analizados estos resultados siguiendo tres ejes: A) Elaboración de reglamentos y de párrafos descriptivos; B) Producción de cuentos y C) Elaboración de enunciados con uso de sinónimos.

A). El promedio en el desempeño de los niños en elaboración de reglamentos y de párrafos descriptivos, en una escala de 0 a 4, aumentó en comparación antes y después de la intervención, conforme se incrementó el nivel de complejidad de desligamiento funcional. En el grupo transituacional se dieron incrementos muy marcados en ambas competencias (1.25 en reglamentos y 2.05 en descripciones), mientras que en el grupo extrasituacional estos cambios fueron moderados $(0.40$ y 0.30 respectivamente), pero en el grupo intrasituacional, en la competencia elaborar reglamentos no hubo algún cambio y en la elaboración de párrafos descriptivos, el cambio fue de 0.37 .

De acuerdo con la teoría que da sustento a este trabajo, un nivel complejo de desligamiento funcional en situaciones de adquisición y ejercicio de competencias de elaborar reglamentos y de párrafos descriptivos, probabilizará una mejor ejecución de estos niños en evaluaciones sistemáticas después de la intervención.

Los datos aportan evidencias que respaldan estos supuestos, por ejemplo, los participantes del grupo transituacional se mostraron más competentes que los niños de los otros dos grupos en actividades de elaboración de reglamentos. Cabe destacar que la elaboración de reglamentos involucra aspectos normativos y valores que son más de tipo convencional y simbólico. 
Es evidente que cuando se promueven interacciones en las que el niño elabora un reglamento basándose en el análisis previo de símbolos y opiniones de otros niños y de otras fuentes y tomando en cuenta el uso de enlaces y expresiones de condicionalidad, el niño tendrá un dominio más complejo en situaciones de evaluación, en contraste con un niño a quien en clases sólo le demandan que transcriba un reglamento (por ejemplo, reglamento de tránsito o un reglamento para el uso de la cancha de basquetbol) o lo elabore tomando literalmente las partes de un texto que debe leer previamente.

Los datos también mostraron que la competencia de redactar párrafos descriptivos, fue influida por el tipo de desligamiento que se promueve en contextos de aprendizaje, es decir, el nivel funcional de entrenamiento tuvo un efecto diferencial en el desempeño de los estudiantes en la pos evaluación, por ejemplo, en el grupo transituacional hubo mayor incremento en la elaboración de párrafos o enunciados descriptivos.

La elaboración de párrafos descriptivos fue incluida como actividad 6 en los grupos intra y transituacional y como actividad 7 en el grupo extra situacional. Estas actividades de elaboración de párrafos descriptivos utilizando cuentos en las situaciones de entrenamiento según el nivel funcional de estructuración de interacciones didácticas, también influyeron de manera diferencial en el nivel de desempeño mostrado en la pos evaluación por los niños de los tres grupos experimentales, en tareas de elaboración de párrafos descriptivos. Por ejemplo, cuando las tareas que demandan que los niños imaginen y luego redacten un párrafo emitiendo su opinión sobre la forma de proceder de los personajes principales de un cuento, tienen un mayor desligamiento de las propiedades del aquí y ahora del referente, en contraste con tareas en que los niños deben redactar un párrafo sobre las características comportamentales y atributos no físicos de los personajes de ese mismo cuento, o cuando los niños solamente deben llenar por escrito una lista de personajes principales y secundarios, consultando el cuento.

Es de suma importancia que los estudiantes al término de la primaria posean un dominio aceptable en tareas de producción de textos, pero también es importante el uso de reglamentos y de párrafos descriptivos tanto en la adquisición funcional de la lengua escrita como en el uso de la escritura en la comunicación en contextos no escolarizados. Por una parte, los reglamentos constituyen en muchos casos factores normativos que regulan y rigen las interacciones del individuo y su medio, por otra parte, los párrafos descriptivos son fundamentales para la comunicación por medio de la lengua escrita. Ambas actividades son consideradas esenciales en el currículum de Español en la primaria mexicana y reciben un trato especial como propósitos de aprendizaje y en la estructuración de contenidos de enseñanza y aprendizaje (SEP, 2000).

Los datos de este estudio muestran con claridad la ventaja que tiene el promover en la situación de aprendizaje de producción de textos, interacciones entre el estudiante y los eventos de referencia en niveles de desligamiento extra y tran- 
situacional. Las interacciones didácticas de producción de textos en niveles funcionalmente más complejos, promovieron competencias en niveles lingüísticos también complejos, y posibilitaron su estructuración ante eventos de referencia novedosos y diferentes a los eventos de referencia que fueron incluidos en las situaciones de aprendizaje.

B). Respecto a la competencia en tareas de redacción de cuentos, los niños de todos los grupos obtuvieron el promedio de desempeño más alto en contraste con las otras tres competencias evaluadas, tanto en la pre evaluación como en la pos evaluación, sin embargo, solamente en los dos grupos con mayor nivel de desligamiento se presentaron incrementos en comparación antes y después de la intervención

Hay dos elementos que podrían explicar estos resultados. Por un lado, la elaboración de cuentos es una de las competencias que más y mejor se trabaja en la escuela primaria mexicana, como pueden observarse en los programas de Español y los libros de texto, lo cual se refleja en el nivel de dominio en la pre evaluación en los tres grupos, pese a que estos niños en general habían salido con indicadores de bajo desempeño en producción de textos.

Por otro lado, el criterio de inclusión fue que los niños seleccionados debían tener desempeños menores a dos puntos al menos en dos de las cuatro competencias evaluadas, pero el promedio inicial en elaboración de cuentos en los tres grupos fue superior a 2.40. Este es un criterio que se debe cuidar con mayor precisión para trabajos posteriores que busquen probar la efectividad de estrategias metodológicas diferenciadas por el tipo de desligamiento funcional que promueven, sobre el desempeño de los niños en elaboración de cuentos.

Una vez resuelto el punto anterior, habría que revisar, probar y mejorar el apego de las actividades en el nivel transituacional a los fundamentos de la teoría de la conducta y los niveles de desligamiento funcional propuestos, en la elaboración de cuentos, y separar las actividades de elaboración de cuentos, de las actividades de elaborar párrafos descriptivos.

C). Con relación a la competencia "elaboración de enunciados con uso de sinónimos", los tres grupos experimentales mostraron cambios en las evaluaciones pre y pos tratamiento, siendo el grupo extrasituacional el que obtuvo mejores indicadores de incremento (1.80) seguido por el grupo intrasituacional (1.63) y por el grupo transituacional (1.00).

De las cuatro competencias evaluadas, elaborar enunciados con uso de sinónimos no fue entrenada de manera diferencial de acuerdo con el nivel de desligamiento funcional que se promovió, ésta se derivó a partir de las dos primeras sesiones de la intervención, en las que fueron desarrolladas actividades de ortografía y vocabulario

(Ortolotería y Sinons). Si bien es cierto que estas actividades corresponden más bien a niveles de desligamiento intrasituacional, son la base para competencias de mayor complejidad morfológica y funcional, como el redactar cuentos, elaborar descripciones, instrucciones y reglamentos. 
En general, estos hallazgos apoyan la necesidad de trabajar en las situaciones de enseñanza y aprendizaje de la lengua escrita en la primaria, estableciendo interacciones entre los niños y los eventos de referencia, transformando relaciones que dependen de las propiedades situacionales de los eventos de referencia, en relaciones que dependen de las propiedades convencionales de las mismas y en relaciones simbólicas o culturales y no físicas. Estos resultados coinciden con los hallazgos derivados de estudios bajo la perspectiva interconductual que respaldan el supuesto que cuando los maestros establecen relaciones entre los niños y el referente en niveles funcionalmente más complejos, los niños tienden a interactuar en situaciones de evaluación también en niveles cualitativamente más complejos (Bazán, 2002; Guevara, Mares, Rueda, Rivas, Sánchez \& Rocha, 2005; Mares, Guevara, Rueda, Rivas \& Rocha, 2004).

Este estudio de ninguna manera supone que una intervención experimental promoviendo un desligamiento funcional intrasituacional no sea efectiva, como podría parecer, dado que estudios en situaciones con mayor control experimental han demostrado su importancia en la adquisición y transferencia de competencias lingüísticas, debido a que los niveles de desarrollo funcional son inclusivos y no son etapas yuxtapuestas entre sí y dado que la estructuración de competencias lingüísticas en situaciones de enseñanza demandan también la estructuración de interacciones en niveles funcionales menos complejos, para ir generando interacciones en niveles más complejos (Bazán \& Mares, 2002; Mares, Rivas \& Bazán, 2002; Mares, Rueda, Plancarte \& Guevara, 1997; Trigo, Martínez \& Moreno, 1988).

El efecto de la situación experimental sobre competencias de producción de textos en diferentes alumnos, está estrechamente relacionado con las interrelaciones funcionales estructuradas que son críticas para que un procedimiento de enseñanza resulte en el aprendizaje de una competencia, y tiene que ver con la procuración de condiciones y circunstancias propicias para el aprendizaje individual (Ribes, 2004).

Por otra parte, respecto a las implicaciones de este estudio con la problemática de la enseñanza de la lengua escrita, en particular de la producción de textos, dos son los aspectos que deben ser considerados:

1. Los datos obtenidos en la pos evaluación conducen a la reflexión sobre el tipo de interacciones que se estructuran en situaciones de enseñanza aprendizaje de la lengua escrita en las escuelas mexicanas, especialmente del trabajo de producción de textos en la primaria, y sobre el nivel de interacción que sugieren los contenidos temáticos y las actividades incluidos en los libros de texto. Si éstos solamente promueven que los estudiantes entren en contacto con los eventos referentes (temas o contenidos) sin desligarse de las relaciones concretas situacionales en las que se presentan en el contexto en el que interactúan, es muy difícil lograr que los niños sean competentes, variados y efectivos en situaciones novedosas que demanden niveles de comprensión, abstracción y elaboración de textos en niveles funcionalmente más complejos. 
2. La escritura se muestra como un aprendizaje sin resolver en la escuela pública mexicana, y su impacto en el nivel de dominio de competencias de escritura de los niños no parece ser del todo satisfactorio, como sugieren diversas evaluaciones nacionales e internacionales que incluyen la escritura en contextos que se caracterizan en muchos de los casos, por situaciones de enseñanza que se estructuran solamente en niveles intrasituacionales: descriptivos y literales.

Si bien es cierto que este estudio mostró la efectividad de estrategias que estructuran y desarrollan interacciones didácticas en niveles funcionalmente más complejos, y que permiten mejorar la calidad de las competencias de producción de textos en estudiantes con bajo desempeño en evaluaciones con contenidos incluidos en el programa de estudios y los libros de texto gratuito, será necesario probar el impacto de este tipo de estrategias en un contexto más amplio que incluya, mayor número de niños, mayor número de contenidos temáticos de escritura y periodos de tiempo más prolongados.

\section{Referencias}

Austin, J. L. (1962). How to do things with words. Oxford: Oxford University Press. Bazán, A. (2002). Interacciones maestro-alumno en una situación de enseñanza de la lengua escrita. Revista de Psicología, 20, 225-252.

Bazán, A., Castañeda, S., Macotela, S., \& López, M. (2004). Evaluación del desempeño en lectura y escritura. Aportes empíricos a la noción de componentes lingüísticos en el cuarto grado de primaria. Revista Mexicana de Investigación Educativa, 9, 841-861.

Bazán, A., \& Mares, G. (2002). Influencia del nivel funcional de entrenamiento en la elaboración relacional en tareas de ejecución verbal. Revista Mexicana de Análisis de la Conducta, 28,19-39.

Bazán, A., Rivera, W., Monroy, A., \& Rodríguez V. (2006). Estudio comparativo entre niños de Morelos y Sinaloa en competencias de Lectura, Escritura y Reflexión sobre la lengua, en quinto grado de primaria. Revista Mexicana de Psicología, 23, 150-151.

Bazán, A., Sánchez, B., \& Castañeda, S. (2007). Relación estructural entre apoyo familiar, nivel educativo de los padres, características del maestro, y desempeño en lengua escrita. Revista Mexicana de Investigación Educativa, 12, 701729.

Cassany, D. (1999). Construir la escritura. Barcelona: Paidós.

Guevara, Y., Mares, G., Rueda, E., Rivas, O., Sánchez, B., \& Rocha, H. (2005). Niveles de interacción que se propician en alumnos de educación primaria durante la enseñanza de la materia español. Revista Mexicana de Análisis de la Conducta, 31, 23-45.

Kantor, J. R. (1924). Principles of Psychology. Ohio: Principia press.

Kantor J. R. (1936). An objetive psychology of grammar. Bloomington: Principia 
press.

Kantor, J. R. (1971). The Aim and progress of psychology and other sciences. Chicago: The Principia Press.

Kantor, J. R. (1977). Psychological linguistics. Chicago: Principia press.

Mares, G., Guevara, Y., \& Rueda, E. (1996). Modificación de referencias orales y escritas a través de un entrenamiento en lectura. Revista Interamericana de Psicología, 30, 189-207.

Mares, G., Guevara, Y., Rueda, E., Rivas, O., \& Rocha, H. (2004). Análisis de interacciones maestra - alumnos durante la enseñanza de las ciencias naturales en primaria. Revista Mexicana de Investigación Educativa, 7, 603-625.

Mares, G., Rivas, O. \& Bazán, A. (2001). Factores de entrenamiento que incrementan la probabilidad de relacionar lingüísticamente objetos u organismos de manera condicional, causal y funcional. Revista Latina de Pensamiento y Lenguaje, 9, 81 - 103.

Mares, G., Rivas, O., \& Bazán, A. (2002). Configuración en el modo escrito de competencias desarrolladas en forma oral como efecto del nivel funcional de ejercicio. Revista Mexicana de análisis de la Conducta, 28, 173-190.

Mares, G., Rueda, E., Plancarte, P., \& Guevara, Y. (1997). Conducta referencial no entrenada: El papel que juega el nivel funcional de entrenamiento en la generalización. Acta Comportamentalia, 5,199-219.

Pacheco, V., \& Villa, J. (2005). El comportamiento del escritor y la producción de textos científicos. Revista Mexicana de Investigación Educativa, 10, 1201 1224.

Ribes, E., \& López, F. (1985). Teoría de la conducta. Un análisis de campo y paramétrico. México: Trillas.

Ribes, E. (2004). Psicología, educación y análisis de la conducta. En S. Castañeda (Editora), Educación, Aprendizaje y Cognición. Teoría en la práctica. México: Editorial el Manual Moderno, pp. 15-26.

Rueda, E., Rivas, O., \& Mares, G. (2003). Una comparación entre programas en lectores principiantes. Revista Mexicana de Psicología, 20, 247-253.

Secretaría de Educación Pública SEP (2000). Programas de estudio de Español Educación primaria. México: Secretaría de Educación Pública.

Secretaría de Educación Pública SEP (2002). Libro de español quinto grado. México: Secretaría de Educación Pública.

Trigo, E., Martínez, R., \& Moreno, R. (1988). Niveles funcionales en la comunicación educativa. En L. Amador (Coordinador), La Psicología hoy: algunos campos de actuación. Sevilla: UNED, 99-116.

Van Dijk, T. (2000). El discurso como interacción social. Barcelona: Gedisa.

Wittgenstein, L. (1953). Philosophical investigations. Oxford: Basil Blackwell. 